\title{
Mobile phones, cordless phones and the risk for brain tumours
}

\author{
LENNART HARDELL and MICHAEL CARLBERG
}

Department of Oncology, Örebro University Hospital, SE-701 85 Örebro, Sweden

Received February 19, 2009; Accepted April 13, 2009

DOI: 10.3892/ijo_00000307

\begin{abstract}
The Hardell-group conducted during 1997-2003 two case control studies on brain tumours including assessment of use of mobile phones and cordless phones. The questionnaire was answered by $905(90 \%)$ cases with malignant brain tumours, 1,254 (88\%) cases with benign tumours and 2,162 (89\%) population-based controls. Cases were reported from the Swedish Cancer Registries. Anatomical area in the brain for the tumour was assessed and related to side of the head used for both types of wireless phones. In the current analysis we defined ipsilateral use (same side as the tumour) as $\geq 50 \%$ of the use and contralateral use (opposite side) as $<50 \%$ of the calling time. We report now further results for use of mobile and cordless phones. Regarding astrocytoma we found highest risk for ipsilateral mobile phone use in the $>10$ year latency group, $\mathrm{OR}=3.3,95 \% \mathrm{CI}=2.0-5.4$ and for cordless phone use $\mathrm{OR}=5.0,95 \% \mathrm{CI}=2.3-11$. In total, the risk was highest for cases with first use $<20$ years age, for mobile phone $\mathrm{OR}=5.2,95 \% \mathrm{CI}=2.2-12$ and for cordless phone $\mathrm{OR}=4.4,95 \% \mathrm{CI}=1.9-10$. For acoustic neuroma, the highest OR was found for ipsilateral use and $>10$ year latency, for mobile phone $\mathrm{OR}=3.0,95 \% \mathrm{CI}=1.4-6.2$ and cordless phone $\mathrm{OR}=2.3,95 \% \mathrm{CI}=0.6-8.8$. Overall highest $\mathrm{OR}$ for mobile phone use was found in subjects with first use at age $<20$ years, $\mathrm{OR}=5.0,95 \%$ CI $1.5-16$ whereas no association was found for cordless phone in that group, but based on only one exposed case. The annual age-adjusted incidence of astrocytoma for the age group $>19$ years increased significantly by $+2.16 \%, 95 \%$ CI +0.25 to +4.10 during 2000-2007 in Sweden in spite of seemingly underreporting of cases to the Swedish Cancer Registry. A decreasing incidence was found for acoustic neuroma during the same period. However, the medical diagnosis and treatment of this tumour type has changed during recent years and underreporting from a single center would have a large impact for such a rare tumour.
\end{abstract}

Correspondence to: Dr Lennart Hardell, Department of Oncology, Örebro University Hospital, SE-701 85 Örebro, Sweden E-mail: lennart.hardell@orebroll.se

Key words: astrocytoma, acoustic neuroma, meningioma, age groups, incidence, wireless phones, survival, attributable fraction

\section{Introduction}

During the last decade there was a rapid increase in the use of wireless phones and the prevalence has reached $100 \%$ in many countries. Concerns about different health risks have been raised, particularly an increased risk for brain tumours (1). The ipsilateral brain (same side as the mobile phone has predominantly been used) is most exposed, whereas the contralateral side (opposite side to the mobile phone) is much less exposed (2). It is thus of vital importance to have information on the localisation of the tumour in the brain and which side of the head that has predominantly been used during phone calls.

Studies in this area have been hampered by rather short latencies for the different types of wireless phones. In general carcinogenesis usually takes decades from first exposure to manifest cancer, although shorter latencies have been implicated for promoters and certain types of diseases, e.g. ionising radiation and leukemia (3-5). Sweden was one of the first countries in the world to adopt this new technology so studies with longer latencies are possible and health effects from the wireless technology may be especially pertinent in our country for early warnings. Analogue phones (NMT, Nordic Mobile Telephone System) were introduced on the market in the early 1980s using both 450 and 900 Megahertz (MHz) fields. NMT 450 was used in Sweden beginning in 1981 and ending in December 31, 2007, whereas NMT 900 operated from 1986 to 2000.

The market is now dominated by the digital system (GSM, Global System for Mobile Communication) that started in 1991 and uses dual band, 900 and 1,800 MHz. The third generation of mobile phones, $3 \mathrm{G}$ or UMTS (Universal Mobile Telecommunication System), using 1,900 MHz RF fields has been introduced around the world more recently, in Sweden since 2003. The desktop cordless phones (Digital Enhanced Cordless Telecommunication, cordless phone) have been used in Sweden since 1988, first analogue 800-900 MHz RF fields, but since early 1990s the digital 1,900 MHz system has been used.

Results from the Hardell-group have been published previously on the association between use of mobile or cordless phones and brain tumours. All studies were approved by the local Ethics Committee. These studies are briefly discussed in the following and additional results are presented on e.g. age-dependent brain tumour risk. The aim of this presentation is not to give a review of this area, since such publications can be found elsewhere $(6,7)$. In addition to our studies only a few publications from the so-called Interphone group give results 
for 10-year latency (7). That group includes 13 countries and cases and controls were recruited during 1999-2004, varying for different countries. For unclear reasons the final results have not yet been published.

In 1999 we published results from our first case control study on brain tumours and use of mobile phones (8). In total $209(90 \%)$ of the cases and $425(91 \%)$ of the controls that fullfilled the inclusion criteria answered the mailed questionnaire. Overall we did not find an association. For ipsilateral exposure we saw a somewhat increased risk (9). These results were based on low numbers of exposed subjects and short latency periods, so no firm conclusions could be drawn. Furthermore, in this first study we did not include the use of cordless phone.

This initial study was followed by two larger studies by us on the same topic. The aim of this paper was to report results from further analyses of these large studies, as will be presented below.

The second case control study included cases diagnosed during the time period January 1, 1997 through June 30, 2000 and population-based controls. All cases were reported to a cancer registry and had histopathological verfication of tumour diagnosis. The study included the use of cordless phones, as well as asking more questions on e.g. occupational exposures. Use of wireless phones was carefully assessed by a selfadministered questionnaire. The information was supplemented over the phone, if necessary. The ear that had mostly been used during calls with mobile phone and/or cordless phone was assessed by separate questions; $>50 \%$ of the time for one side, or equally both sides. This information was checked during the supplementary phone call. Moreover, every person that had used a mobile phone received after that a letter asking them again to specify the ear that had been used during phone calls and to what extent that side of the head was mostly used, e.g. 100, 70 and 50\% etc. There was a very good agreement for the result using these three methods to assess these data.

Separately, tumour localisation was defined by using medical records, such as computer tomography (CT) and/or magnetic resonance imaging (MRI). After that use of the wireless phone was defined as ipsilateral ( $>50 \%$ of the time), equally ipsi/contralateral or contralateral $(<50 \%)$ in relation to tumour side. The tumour type was defined by using histopathology studies. In the calculation of cumulative hours of use over the years we used information of first and last year for use (time period) and average number of minutes per day during that period. Use in a car with external antenna was disregarded as well as use of a handsfree device. We adopted a minimum latency period of one year. Hence, we could define latency period and cumulative use for the different phone types.

Only living subjects were included in our studies and this second case control study included 1,429 (88\%) cases and $1,470(91 \%)$ controls. The results regarding use of wireless phones have been published previously (10-13).

This study was followed by our third case control study on the same topic. The methods were the same as in the second study using an identical questionnaire. The study period was from July 1, 2000 until December 31, 2003. In total 729 (89\%) cases and $692(84 \%)$ controls participated, as previously published $(14,15)$.
We made pooled analysis of the two case control studies on brain tumour cases diagnosed 1997-2003, both malignant (16) and benign (17). This was possible since the same methods were used in both studies with an identical questionnaire. For more details about the study design, see our previous publications.

\section{Materials and methods}

We have previously reported findings for different age groups at the time of diagnosis in the study with inclusion period 1997-2000 (18). Now we have re-analysed the whole study period 1997-2003, especially in regard to age at the first time for use of a wireless phone and the association with different types of brain tumours. We analysed also type of phone and laterality of tumour according to the method by Inskip et al (19). Furthermore, we evaluated the risk for tumour for men and women separately, anatomical localisations in the brain, latency for first use of mobile phone or cordless phone, survival and incidence of brain tumours in Sweden.

We used three age groups for first use of a wireless phone; $<20$ years, 20-49 years and 50-80 years. For laterality analysis of tumour in relation to phone use one group consisted of ipsilateral and varying ipsi/contralateral use (in the following called ipsilateral), the other of contralateral use. The malignant brain tumours $(n=905)$ were divided into astrocytoma grade I-IV ( $n=663)$, oligodendroglioma $(n=93)$, other/mixed glioma $(n=78)$ and other types (medulloblastoma $n=6$, ependymoma $n=19$, other types $n=46$ ). The benign tumours $(n=1,254)$ were divided into acoustic neuroma $(n=243)$, meningioma $(n=916)$ and other types $(n=96)$. One case had both acoustic neuroma and meningioma and another case had both 'other type' malignant tumour and acoustic neuroma.

Statistical methods. All analyses were done using StataSE 10.1 (Stata/SE 10.1 for Windows; StataCorp., College Station, TX). Odds ratio (OR) and $95 \%$ confidence interval (CI) were calculated using unconditional logistic regression analysis. The unexposed category consisted of subjects that reported no use of mobile or cordless phones. Adjustment was made for gender, age (as a continuous variable), socio-economic index (SEI) and year of diagnosis. The same year as for the case was used for the corresponding control. Ipsilateral use of a wireless phone was defined here as $\geq 50 \%$ on the tumour side. Note, that laterality of the tumour was not available for all cases, e.g., midline tumours or tumours in both hemispheres.

\section{Results}

Malignant brain tumours. For malignant brain tumours we obtained answers from 905 (90\%) cases (16). For reference the whole control population of 2,162 (89\%) subjects during 1997-2003 was used.

Different malignant tumour types. Regarding mobile phones $\mathrm{OR}=1.4,95 \% \mathrm{CI}=1.1-1-7$ was calculated for astrocytoma grade I-IV, increasing to $\mathrm{OR} 2.0,95 \% \mathrm{CI}=1.5-2.5$ for ipsilateral use, whereas no increased risk was found for contralateral use, Table I. Using >10-year latency time yielded higher ORs and 
Table I. Odds ratio (OR) and 95\% confidence interval (CI) for astrocytoma grade I-IV (n=663).

Age at first exposure/

Type of telephone

All Ca/Co OR (CI) Ipsilateral + Ipsi/contralateral Ca/Co OR (CI) Contralateral Ca/Co OR (CI)

\begin{tabular}{|c|c|c|c|}
\hline \multicolumn{4}{|l|}{ All } \\
\hline Mobile phone, & $346 / 900$ & $229 / 374$ & $98 / 308$ \\
\hline \multirow[t]{2}{*}{$>1$ year latency } & 1.4 & 2.0 & 1.0 \\
\hline & $1.1-1.7$ & $1.5-2.5$ & $0.7-1.4$ \\
\hline \multirow[t]{3}{*}{$>10$ year latency } & 78/99 & $50 / 45$ & $26 / 29$ \\
\hline & 2.7 & 3.3 & 2.8 \\
\hline & $1.8-3.9$ & $2.0-5.4$ & $1.5-5.1$ \\
\hline \multicolumn{4}{|l|}{ Cordless phone, } \\
\hline \multirow[t]{3}{*}{$>1$ year latency } & $261 / 701$ & $167 / 309$ & $81 / 235$ \\
\hline & 1.4 & 1.8 & 1.2 \\
\hline & $1.1-1.8$ & $1.4-2.4$ & $0.8-1.6$ \\
\hline \multirow[t]{3}{*}{$>10$ year latency } & $28 / 45$ & $19 / 15$ & $8 / 20$ \\
\hline & 2.5 & 5.0 & 1.4 \\
\hline & $1.4-4.4$ & $2.3-11$ & $0.6-3.5$ \\
\hline \multicolumn{4}{|l|}{$<20,>1$ year latency } \\
\hline \multirow[t]{3}{*}{ Mobile phone } & $15 / 14$ & $8 / 5$ & $2 / 4$ \\
\hline & 5.2 & 7.8 & 2.2 \\
\hline & $2.2-12$ & $2.2-28$ & $0.4-13$ \\
\hline \multicolumn{4}{|l|}{ Cordless phone } \\
\hline & $14 / 16$ & $9 / 6$ & $1 / 4$ \\
\hline & 4.4 & 7.9 & 1.1 \\
\hline & $1.9-10$ & $2.5-25$ & $0.1-10$ \\
\hline \multicolumn{4}{|c|}{$20-49,>1$ year latency } \\
\hline \multirow[t]{3}{*}{ Mobile phone } & $208 / 555$ & $131 / 221$ & $67 / 198$ \\
\hline & 1.5 & 2.1 & 1.2 \\
\hline & $1.1-2.0$ & $1.5-2.9$ & $0.8-1.8$ \\
\hline \multirow[t]{3}{*}{ Cordless phone } & $138 / 416$ & $83 / 179$ & $50 / 154$ \\
\hline & 1.3 & 1.6 & 1.2 \\
\hline & $0.98-1.8$ & $1.1-2.4$ & $0.8-1.8$ \\
\hline \multicolumn{4}{|c|}{$50-80,>1$ year latency } \\
\hline \multirow[t]{3}{*}{ Mobile phone } & $123 / 331$ & $90 / 148$ & $29 / 106$ \\
\hline & 1.3 & 1.8 & 0.8 \\
\hline & $0.97-1.7$ & $1.3-2.5$ & $0.5-1.3$ \\
\hline \multirow[t]{3}{*}{ Cordless phone } & $109 / 269$ & $75 / 124$ & $30 / 77$ \\
\hline & 1.5 & 1.9 & 1.2 \\
\hline & $1.1-2.0$ & $1.3-2.7$ & $0.8-1.9$ \\
\hline
\end{tabular}

anumbers of exposed cases (Ca) and controls (Co) are given. Adjustment was made for age, gender, SEI and year of diagnosis.

regarding mobile phone use also contralateral use gave a significantly increased risk. We also analysed astrocytoma grade I-II and III-IV separately with no clear difference, although the $>10$ year latency group had few exposed cases in these calculations (data not shown).

For different age groups highest OR for astrocytoma was found for the subjects that had started the use of a mobile phone at age $<20$ years, $\mathrm{OR}=5.2,95 \% \mathrm{CI}=2.2-12$, higher for ipsilateral use $\mathrm{OR}=7.8,95 \% \mathrm{CI}=2.2-28$, Table I. Similar results were found for use of cordless phone. Thus, first use at age $<20$ years yielded $\mathrm{OR}=4.4,95 \% \mathrm{CI}=1.9-10$ increasing to $\mathrm{OR}=7.9,95 \% \mathrm{CI}=2.5-25$ for ipsilateral use. Lower ORs were calculated for both mobile phones and cordless phones in the two older age groups. No significantly decreased or increased risks were found for contralateral use in the analysed age groups.

For oligodendroglioma and other/mixed glioma no significantly increased risks were found, Table II. In the group of 'other' malignant brain tumours significantly increased risk was found for mobile phone use, $>10$ year latency, $\mathrm{OR}=3.2,95 \% \mathrm{CI}=1.2-8.8$ increasing for ipsilateral use to $\mathrm{OR}=4.1,95 \% \mathrm{CI}=1.03-16$. Analysis of different entities in the group of 'other' malignant brain tumours gave significantly increased OR only for a heterogenic group of 
Table II. Odds ratio (OR) and 95\% confidence interval (CI) for other malignant brain tumours. ${ }^{\mathrm{a}}$

Age at first exposure/

Type of telephone

All Ca/Co OR (CI) Ipsilateral + Ipsi/contralateral Ca/Co OR (CI) Contralateral Ca/Co OR (CI)

\begin{tabular}{|c|c|c|c|}
\hline \multicolumn{4}{|c|}{ Oligodendroglioma $(n=93)$} \\
\hline Mobile phone, & $51 / 900$ & $28 / 374$ & $21 / 308$ \\
\hline \multirow[t]{2}{*}{$>1$ year latency } & 1.5 & 1.7 & 1.3 \\
\hline & $0.9-2.4$ & $0.9-3.0$ & $0.7-2.4$ \\
\hline \multirow[t]{3}{*}{$>10$ year latency } & $5 / 99$ & $3 / 45$ & $2 / 29$ \\
\hline & 1.6 & 1.6 & 2.1 \\
\hline & $0.5-4.8$ & $0.4-6.1$ & $0.4-11$ \\
\hline \multicolumn{4}{|l|}{ Cordless phone, } \\
\hline \multirow[t]{3}{*}{$>1$ year latency } & $38 / 701$ & $16 / 309$ & $19 / 235$ \\
\hline & 1.4 & 1.1 & 1.7 \\
\hline & $0.8-2.5$ & $0.5-2.1$ & $0.9-3.2$ \\
\hline \multirow[t]{3}{*}{$>10$ year latency } & $3 / 45$ & $1 / 15$ & $2 / 20$ \\
\hline & 1.8 & 1.1 & 2.5 \\
\hline & $0.4-7.2$ & $0.1-11$ & $0.5-13$ \\
\hline \multicolumn{4}{|c|}{ Other/mixed glioma $(\mathrm{n}=78)$} \\
\hline Mobile phone, & $35 / 900$ & $22 / 374$ & $13 / 308$ \\
\hline \multirow[t]{2}{*}{$>1$ year latency } & 1.0 & 1.1 & 1.0 \\
\hline & $0.6-1.7$ & $0.6-2.1$ & $0.5-2.0$ \\
\hline \multirow[t]{3}{*}{$>10$ year latency } & $5 / 99$ & $4 / 45$ & $1 / 29$ \\
\hline & 1.8 & 2.7 & 1.1 \\
\hline & $0.6-5.3$ & $0.8-9.2$ & $0.1-9.5$ \\
\hline \multirow{3}{*}{$\begin{array}{l}\text { Cordless phone, } \\
>1 \text { year latency }\end{array}$} & $26 / 701$ & $17 / 309$ & $9 / 235$ \\
\hline & 1.0 & 1.1 & 0.8 \\
\hline & $0.5-1.7$ & $0.6-2.3$ & $0.3-1.8$ \\
\hline \multirow[t]{3}{*}{$>10$ year latency } & $1 / 45$ & $0 / 15$ & $1 / 20$ \\
\hline & 0.9 & - & 1.4 \\
\hline & $0.1-7.5$ & & $0.1-13$ \\
\hline \multicolumn{4}{|c|}{ Other malignant ( $n=71 ;$ medulloblastoma $-n=6$, ependymoma $-n=19$, other $-n=46$ ) } \\
\hline \multirow{3}{*}{$\begin{array}{l}\text { Mobile phone, } \\
>1 \text { year latency }\end{array}$} & $36 / 900$ & $15 / 374$ & $5 / 308$ \\
\hline & 1.2 & 1.3 & 0.4 \\
\hline & $0.7-2.1$ & $0.6-2.8$ & $0.1-1.3$ \\
\hline \multirow[t]{3}{*}{$>10$ year latency } & $8 / 99$ & $4 / 45$ & $1 / 29$ \\
\hline & 3.2 & 4.1 & 1.7 \\
\hline & $1.2-8.8$ & $1.03-16$ & $0.2-15$ \\
\hline \multirow{3}{*}{$\begin{array}{l}\text { Cordless phone, } \\
>1 \text { year latency }\end{array}$} & $25 / 701$ & 7/309 & $7 / 235$ \\
\hline & 1.1 & 0.7 & 0.9 \\
\hline & $0.6-2.0$ & $0.3-1.8$ & $0.3-2.3$ \\
\hline \multirow[t]{3}{*}{$>10$ year latency } & $1 / 45$ & $0 / 15$ & $1 / 20$ \\
\hline & 1.1 & - & 3.9 \\
\hline & $0.1-10$ & & $0.3-44$ \\
\hline
\end{tabular}

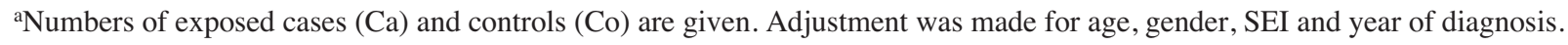

4 cases with ipsilateral use. Due to low numbers it was not meaningful to make separate calculations for different age groups of first use of a wireless phone.

Benign brain tumours. Our other pooled analysis reported results for the benign brain tumours from the same study period 1997-2003 (17). The questionnaire was answered by $1,254(88 \%)$ cases and the same control group as for malignant brain tumours was used, $n=2,162(89 \%$ respondents).
Acoustic neuroma. Use of mobile phones gave for acoustic neuroma $\mathrm{OR}=1.7,95 \% \mathrm{CI} 1.2-2.3$, and cordless phones $\mathrm{OR}=1.5,95 \% \mathrm{CI}=1.04-2.0$, Table III. These ORs increased further for ipsilateral use whereas no significantly increased ORs were found for contralateral use. Using $>10$ year latency period for mobile phones gave $\mathrm{OR}=2.9,95 \% \mathrm{CI}=1.6-5.5$ and for cordless phones $\mathrm{OR}=1.3,95 \%$ CI 0.4-3.8.

Regarding different age groups highest risk was found for first use of a mobile phone at age $<20$ years, $\mathrm{OR}=5.0,95 \%$ $\mathrm{CI}=1.5-16$, increasing to $\mathrm{OR}=6.8,95 \% \mathrm{CI}=1.4-34$ for 
Table III. Odds ratio (OR) and 95\% confidence interval (CI) for acoustic neuroma ( $\mathrm{n}=243){ }^{\mathrm{a}}$

Age at first exposure/

Type of telephone

All Ca/Co OR (CI) Ipsilateral + Ipsi/contralateral Ca/Co OR (CI) Contralateral Ca/Co OR (CI)

\begin{tabular}{|c|c|c|c|}
\hline \multicolumn{4}{|l|}{ All } \\
\hline Mobile phone, & $130 / 900$ & $80 / 374$ & $48 / 308$ \\
\hline \multirow[t]{2}{*}{$>1$ year latency } & 1.7 & 1.8 & 1.4 \\
\hline & $1.2-2.3$ & $1.2-2.6$ & $0.9-2.1$ \\
\hline \multirow[t]{3}{*}{$>10$ year latency } & 20/99 & $13 / 45$ & $6 / 29$ \\
\hline & 2.9 & 3.0 & 2.4 \\
\hline & $1.6-5.5$ & $1.4-6.2$ & $0.9-6.3$ \\
\hline \multirow{3}{*}{$\begin{array}{l}\text { Cordless phone, } \\
>1 \text { year latency }\end{array}$} & $96 / 701$ & $67 / 309$ & $28 / 235$ \\
\hline & 1.5 & 1.7 & 1.1 \\
\hline & $1.04-2.0$ & $1.2-2.5$ & $0.7-1.7$ \\
\hline \multirow[t]{3}{*}{$>10$ year latency } & $4 / 45$ & $3 / 15$ & $1 / 20$ \\
\hline & 1.3 & 2.3 & 0.5 \\
\hline & $0.4-3.8$ & $0.6-8.8$ & $0.1-4.0$ \\
\hline \multicolumn{4}{|l|}{$<20,>1$ year latency } \\
\hline \multirow[t]{3}{*}{ Mobile phone } & $5 / 14$ & $3 / 5$ & $1 / 4$ \\
\hline & 5.0 & 6.8 & 2.4 \\
\hline & $1.5-16$ & $1.4-34$ & $0.2-24$ \\
\hline \multirow[t]{3}{*}{ Cordless phone } & $1 / 16$ & $1 / 6$ & $0 / 4$ \\
\hline & 0.7 & 1.7 & - \\
\hline & $0.1-5.9$ & $0.2-16$ & \\
\hline \multicolumn{4}{|c|}{$20-49,>1$ year latency } \\
\hline \multirow[t]{3}{*}{ Mobile phone } & $86 / 555$ & $59 / 221$ & $26 / 198$ \\
\hline & 2.0 & 2.5 & 1.2 \\
\hline & $1.3-2.9$ & $1.6-3.9$ & $0.7-2.0$ \\
\hline \multirow[t]{3}{*}{ Cordless phone } & $65 / 416$ & $48 / 179$ & $16 / 154$ \\
\hline & 1.7 & 2.2 & 0.9 \\
\hline & $1.1-2.5$ & $1.4-3.6$ & $0.5-1.6$ \\
\hline \multicolumn{4}{|c|}{$50-80,>1$ year latency } \\
\hline \multirow[t]{3}{*}{ Mobile phone } & $39 / 331$ & $18 / 148$ & $21 / 106$ \\
\hline & 1.4 & 1.1 & 1.8 \\
\hline & $0.9-2.2$ & $0.6-1.9$ & $1.1-3.2$ \\
\hline \multirow[t]{3}{*}{ Cordless phone } & $30 / 269$ & $18 / 124$ & $12 / 77$ \\
\hline & 1.3 & 1.3 & 1.4 \\
\hline & $0.8-2.1$ & $0.7-2.2$ & $0.7-2.8$ \\
\hline
\end{tabular}

aNumbers of exposed cases $(\mathrm{Ca})$ and controls $(\mathrm{Co})$ are given. Adjustment was made for age, gender, SEI and year of diagnosis .

ipsilateral use, Table III. Only one case had used cordless phone at age $<20$ years. In the age group 20-49 years highest OR was calculated for ipsilateral use of both mobile phone and cordless phone, whereas no significant association was found in the age group 50-80 years. Contralateral use yielded no significant associations, but for the age group 50-80 years with $\mathrm{OR}=1.8,95 \% \mathrm{CI}=1.1-3.2$ for mobile phone.

Meningioma. Regarding meningioma mobile phone use gave $\mathrm{OR}=1.1,95 \% \mathrm{CI}=0.9-1.3$ increasing to $\mathrm{OR}=1.3,95 \%$ $\mathrm{CI}=1.01-1.7$ for ipsilateral use, Table IV. For cordless phones $\mathrm{OR}=1.1,95 \% \mathrm{CI}=0.9-1.4$ and for ipsilateral use $\mathrm{OR}=1.2$, $95 \% \mathrm{CI}=0.9-1.6$ were calculated. Using $>10$ year latency period ORs increased for mobile phones to $\mathrm{OR}=1.5,95 \%$ $\mathrm{CI}=0.98-2.4$, and for cordless phones to $\mathrm{OR}=1.8,95 \%$ $\mathrm{CI}=1.01-3.2$. Ipsilateral exposure gave for mobile phones
$\mathrm{OR}=1.6,95 \mathrm{CI} \%=0.9-2.9$, and for cordless phones $\mathrm{OR}=3.0$, $95 \% \mathrm{CI}=1.3-7.2$, in the $>10$ year latency group.

No clear age-dependent effect was found for meningioma, Table IV. The only significant associations were found for ipsilateral use in the age group 20-49 years, for mobile phone use $\mathrm{OR}=1.6,95 \% \mathrm{CI}=1.1-2.2$ and for cordless phone use $\mathrm{OR}=1.4,95 \% \mathrm{CI}=1.002-2.0$.

Other benign brain tumours. Regarding other types of benign brain tumours no significant associations were found overall, Table V. In the $>10$ year latency group ipsilateral mobile phone use gave $\mathrm{OR}=4.7,95 \% \mathrm{CI}=1.1-21$. Due to low numbers no separate calculations were made for different age groups. All of these four cases belonged to a heterogenic group of 'other' benign brain tumours. 
Table IV. Odds ratio (OR) and 95\% confidence interval (CI) for meningioma ( $\mathrm{n}=916){ }^{\mathrm{a}}$

Age at first exposure/

Type of telephone

$\mathrm{All} \mathrm{Ca} / \mathrm{Co} \mathrm{OR}(\mathrm{CI}) \quad$ Ipsilateral + Ipsi/contralateral $\mathrm{Ca} / \mathrm{Co} \mathrm{OR}(\mathrm{CI}) \quad$ Contralateral $\mathrm{Ca} / \mathrm{Co} \mathrm{OR}(\mathrm{CI})$

\begin{tabular}{|c|c|c|c|}
\hline \multicolumn{4}{|l|}{ All } \\
\hline \multirow{3}{*}{$\begin{array}{l}\text { Mobile phone, } \\
\text { >1 year latency }\end{array}$} & $347 / 900$ & $167 / 374$ & $125 / 308$ \\
\hline & 1.1 & 1.3 & 1.1 \\
\hline & $0.9-1.3$ & $1.01-1.7$ & $0.8-1.4$ \\
\hline \multirow[t]{3}{*}{$>10$ year latency } & $38 / 99$ & $18 / 45$ & $12 / 29$ \\
\hline & 1.5 & 1.6 & 1.6 \\
\hline & $0.98-2.4$ & $0.9-2.9$ & $0.7-3.3$ \\
\hline \multirow{3}{*}{$\begin{array}{l}\text { Cordless phone, } \\
>1 \text { year latency }\end{array}$} & $294 / 701$ & $134 / 309$ & $101 / 235$ \\
\hline & 1.1 & 1.2 & 1.1 \\
\hline & $0.9-1.4$ & $0.9-1.6$ & $0.8-1.5$ \\
\hline \multirow[t]{3}{*}{$>10$ year latency } & $23 / 45$ & $11 / 15$ & $7 / 20$ \\
\hline & 1.8 & 3.0 & 1.1 \\
\hline & $1.01-3.2$ & $1.3-7.2$ & $0.5-2.9$ \\
\hline$<20,>1$ year latency & $5 / 14$ & $2 / 5$ & $1 / 4$ \\
\hline \multirow[t]{2}{*}{ Mobile phone } & 1.9 & 2.2 & 1.7 \\
\hline & $0.6-5.6$ & $0.4-13$ & $0.2-16$ \\
\hline \multirow[t]{3}{*}{ Cordless phone } & $2 / 16$ & $1 / 6$ & $1 / 4$ \\
\hline & 0.5 & 0.6 & 1.0 \\
\hline & $0.1-2.2$ & $0.1-5.8$ & $0.1-9.5$ \\
\hline $20-49,>1$ year latency & $210 / 555$ & $100 / 221$ & $74 / 198$ \\
\hline \multirow[t]{2}{*}{ Mobile phone } & 1.3 & 1.6 & 1.2 \\
\hline & $0.99-1.6$ & $1.1-2.2$ & $0.8-1.7$ \\
\hline \multirow[t]{3}{*}{ Cordless phone } & $167 / 416$ & $79 / 179$ & $54 / 154$ \\
\hline & 1.3 & 1.4 & 1.0 \\
\hline & $0.98-1.6$ & $1.002-2.0$ & $0.7-1.5$ \\
\hline $50-80,>1$ year latency & $132 / 331$ & $65 / 148$ & $50 / 106$ \\
\hline \multirow[t]{2}{*}{ Mobile phone } & 1.0 & 1.1 & 1.1 \\
\hline & $0.8-1.3$ & $0.8-1.5$ & $0.8-1.6$ \\
\hline \multirow[t]{3}{*}{ Cordless phone } & $125 / 269$ & $54 / 124$ & $46 / 77$ \\
\hline & 1.1 & 1.0 & 1.3 \\
\hline & $0.8-1.4$ & $0.7-1.4$ & $0.9-2.0$ \\
\hline
\end{tabular}

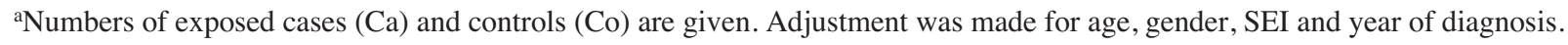

Age for use of wireless phones and latency. The median age for cases with astrocytoma was 53 years for use of both mobile phone and cordless phone with no significant difference between persons that reported ipsilateral or contralateral use. Median age was 60 years for no use of a mobile or cordless phone. There was no significant difference for latency between ipsilateral or contralateral use.

Regarding acoustic neuroma median age among mobile phone users was 51 years and for use of cordless phones 47 years. Median age was not significantly different between persons that reported ipsilateral or contralateral use. Cases with no use of wireless phones had median age 57 years. Latency period was not significantly different between ipsilateral and contralateral use.

Laterality according to Inskip. Laterality of tumour was significantly associated with self-reported laterality of use of a mobile phone or cordless phone among cases with astrocytoma or acoustic neuroma, Table VI. Thus, the relative risk (RR) for mobile phone use was $1.7, \mathrm{p}<0.001$ for astrocytoma and for acoustic neuroma $R R=1.3, p=0.01$. Cordless phone yielded for astrocytoma $R R=1.5, p<0.001$ and for acoustic neuroma $R R=1.7, \mathrm{p}<0.001$.

Anatomical tumour localisation. Tumours of the astrocytoma type were located in the frontal lobe $(n=214)$, parietal $(n=73)$, temporal $(n=169)$, occipital $(n=29)$, multiple lobes (frontal, parietal, temporal; $n=126)$, cerebellum $(n=16)$ and 'other' (multiple or not defined; $n=36$ ). Clearly ipsilateral use of mobile or cordless phones was associated with an increased risk for astrocytoma in the frontal, parietal or temporal lobe (data not in Table). These results were similar, e.g., for the temporal lobe and $>10$ year latency for ipsilateral mobile phone use $\mathrm{OR}=3.0,95 \% \mathrm{CI}=1.4-6.3$ and 
Table V. Odds ratio (OR) and 95\% confidence interval $(\mathrm{CI})$ for other benign brain tumours $(\mathrm{n}=96$ pituaitary adenoma $\mathrm{n}=34$, other $\mathrm{n}=62)$. ${ }^{\mathrm{a}}$

Age at first exposure/

Type of telephone

All Ca/Co OR (CI) Ipsilateral + Ipsi/contralateral Ca/Co OR (CI) Contralateral Ca/Co OR (CI)

\begin{tabular}{lccc}
\hline All & & & \\
Mobile phone, & $49 / 900$ & $11 / 374$ & $12 / 308$ \\
$>1$ year latency & 1.5 & 1.4 & 2.1 \\
& $0.9-2.5$ & $0.5-3.8$ & $0.8-5.3$ \\
$>10$ year latency & $7 / 99$ & $4 / 45$ & $1 / 29$ \\
& 1.8 & 4.7 & 2.6 \\
& $0.7-4.9$ & $1.1-21$ & $0.2-30$ \\
Cordless phone, & $34 / 701$ & $8 / 309$ & $9 / 235$ \\
$>1$ year latency & 1.5 & 1.5 & 2.0 \\
& $0.8-2.5$ & $0.5-4.3$ & $0.7-5.5$ \\
$>10$ year latency & $1 / 45$ & $1 / 15$ & $0 / 20$ \\
& 1.3 & 9.2 & -
\end{tabular}

${ }^{a}$ Numbers of exposed cases $(\mathrm{Ca})$ and controls $(\mathrm{Co})$ are given. Adjustment was made for age, gender, SEI and year of diagnosis.

Table VI. Analysis of laterality according to the method of Inskip et al (19).

\begin{tabular}{|c|c|c|c|c|c|}
\hline \multirow{2}{*}{$\begin{array}{l}\text { Type of phone/laterality } \\
\text { of tumour }\end{array}$} & \multicolumn{3}{|c|}{ Laterality of telephone use } & \multirow[b]{2}{*}{ Relative risk } & \multirow[b]{2}{*}{ P-value } \\
\hline & Left & Right & Total & & \\
\hline \multicolumn{6}{|l|}{ Astrocytoma, grade I-IV } \\
\hline \multicolumn{6}{|l|}{ Mobile phone } \\
\hline -Left & 100 & 58 & 158 & 1.7 & $<0.001$ \\
\hline -Right & 40 & 129 & 169 & & \\
\hline -Total & 140 & 187 & 327 & & \\
\hline \multicolumn{6}{|l|}{ Cordless phone } \\
\hline -Left & 71 & 49 & 120 & 1.5 & $<0.001$ \\
\hline -Right & 32 & 96 & 128 & & \\
\hline -Total & 103 & 145 & 248 & & \\
\hline \multicolumn{6}{|l|}{ Acoustic neuroma } \\
\hline \multicolumn{6}{|l|}{ Mobile phone } \\
\hline -Left & 47 & 23 & 70 & 1.3 & 0.01 \\
\hline -Right & 25 & 33 & 58 & & \\
\hline -Total & 72 & 56 & 128 & & \\
\hline \multicolumn{6}{|l|}{ Cordless phone } \\
\hline -Left & 40 & 15 & 55 & 1.7 & $<0.001$ \\
\hline -Right & 13 & 27 & 40 & & \\
\hline -Total & 53 & 42 & 95 & & \\
\hline
\end{tabular}

aFisher's exact test. Subjects with equal use of both ears were assigned to the same side of telephone use as the side of the tumour.

cordless phone use $\mathrm{OR}=5.6,95 \% \mathrm{CI}=1.9-16$. No association was found for astrocytoma in the cerebellum or 'other' localisation. Regarding the occipital lobe ipsilateral use of mobile phone with latency $>10$ years yielded $\mathrm{OR}=4.8,95 \% \mathrm{CI}=1.1-21(\mathrm{n}=4$ cases $)$ whereas cordless phone did not increase the risk. For astrocytoma in the group of tumour growth in more than one lobe mobile phone use with $>10$ years latency gave $\mathrm{OR}=3.0,95 \%$ $\mathrm{CI}=1.2-7.2$ ( $\mathrm{n}=9$ cases). No association was found for use of cordless phones in this group. 
Table VII. Odds ratio (OR) and 95\% confidence interval (CI) for gender-specific analysis of astrocytoma grade I-IV. ${ }^{\mathrm{a}}$

Age at first exposure/

Type of telephone

$\mathrm{All} \mathrm{Ca} / \mathrm{Co}$ OR (CI) Ipsilateral + Ipsi/contralateral Ca/Co OR (CI) Contralateral Ca/Co OR (CI)

\begin{tabular}{|c|c|c|c|}
\hline \multicolumn{4}{|l|}{ Men $(n=405)$} \\
\hline Mobile phone, & $255 / 503$ & $168 / 215$ & $74 / 165$ \\
\hline \multirow[t]{2}{*}{$>1$ year latency } & 1.6 & 2.2 & 1.2 \\
\hline & $1.2-2.1$ & $1.5-3.1$ & $0.8-1.7$ \\
\hline \multirow[t]{3}{*}{$>10$ year latency } & $69 / 84$ & $45 / 38$ & $22 / 24$ \\
\hline & 2.5 & 3.3 & 2.7 \\
\hline & $1.6-3.8$ & $1.9-5.7$ & $1.3-5.4$ \\
\hline \multirow{3}{*}{$\begin{array}{l}\text { Cordless phone, } \\
>1 \text { year latency }\end{array}$} & $176 / 318$ & $112 / 142$ & $57 / 104$ \\
\hline & 1.8 & 2.1 & 1.5 \\
\hline & $1.3-2.4$ & $1.5-3.1$ & $0.9-2.3$ \\
\hline \multirow[t]{3}{*}{$>10$ year latency } & $19 / 31$ & $13 / 13$ & $6 / 12$ \\
\hline & 2.1 & 4.6 & 1.4 \\
\hline & $1.01-4.4$ & $1.6-13$ & $0.4-4.1$ \\
\hline \multicolumn{4}{|l|}{ Women $(n=258)$} \\
\hline \multirow{3}{*}{$\begin{array}{l}\text { Mobile phone, } \\
>1 \text { year latency }\end{array}$} & $91 / 397$ & $61 / 159$ & $24 / 143$ \\
\hline & 1.2 & 1.7 & 0.8 \\
\hline & $0.8-1.6$ & $1.1-2.5$ & $0.5-1.3$ \\
\hline \multirow[t]{3}{*}{$>10$ year latency } & $9 / 15$ & $5 / 7$ & $4 / 5$ \\
\hline & 3.4 & 3.3 & 4.1 \\
\hline & $1.3-8.4$ & $0.9-11$ & $1.01-16$ \\
\hline \multirow{3}{*}{$\begin{array}{l}\text { Cordless phone, } \\
>1 \text { year latency }\end{array}$} & $85 / 383$ & $55 / 167$ & $24 / 131$ \\
\hline & 1.1 & 1.5 & 0.8 \\
\hline & $0.8-1.5$ & $0.97-2.2$ & $0.5-1.4$ \\
\hline \multirow[t]{3}{*}{$>10$ year latency } & $9 / 14$ & $6 / 2$ & $2 / 8$ \\
\hline & 3.6 & 16 & 1.4 \\
\hline & $1.4-9.3$ & $2.7-90$ & $0.3-7.0$ \\
\hline
\end{tabular}

${ }^{a}$ Numbers of exposed cases (Ca) and controls (Co) are given. Adjustment was made for age, SEI and year of diagnosis.

The same calculations were made for meningioma. Regarding $>10$ year latency and ipsilateral use of mobile phone significant association was found for meningioma in the parietal lobe, $\mathrm{OR}=3.8,95 \% \mathrm{CI}=1.2-12$ ( $\mathrm{n}=5$ cases) and temporal lobe, $\mathrm{OR}=3.1,95 \% \mathrm{CI}=1.2-8.2$ ( $\mathrm{n}=7$ cases). In the same group, cordless phone use significantly increased the risk for meningioma in the temporal lobe, $\mathrm{OR}=10,95 \%$ $\mathrm{CI}=3.1-34$ ( $\mathrm{n}=6$ cases). No significant associations were found for the other localisations.

Gender-specific analysis. We made gender-specific analyses for astrocytoma and acoustic neuroma. We found a clear association for both genders. Mobile phone use increased the risk for astrocytoma in men, $\mathrm{OR}=1.6,95 \% \mathrm{CI}=1.2-2.1$ increasing further to $\mathrm{OR}=2.5,95 \% \mathrm{CI}=1.6-3.8$ in the $>10$ year latency group. The results for women were $\mathrm{OR}=1.2,95 \%$ $\mathrm{CI}=0.8-1.6$ and $\mathrm{OR}=3.4,95 \% \mathrm{CI}=1.3-8.4$, respectively, Table VII. Also use of cordless phones increased the risk.

Similar calculations for acoustic neuroma yielded a pattern of an association both for men and women, although some of the calculations were based on low numbers, Table VIII.
Attributable fraction. Attributable fraction (AF) is the proportion of cases that can be attributed to the particular exposure. This is calculated as the exposed case fraction multiplied by [(OR-1)/OR]. For astrocytoma grade I-IV use of mobile phone and/or cordless phone yielded $\mathrm{AF}=16.8 \%$ corresponding to 111 cases (95\% $\mathrm{CI}=39-169$ cases). $\mathrm{AF}$ for acoustic neuroma was calculated to $20.4 \%$, or 50 cases $(95 \%$ $\mathrm{CI}=13-77$ cases $)$.

Survival. Survival for patients with astrocytoma is agedependent with better prognosis for younger individuals. We found differences in age for subjects that used wireless phones compared with non-users, see above. Thus, we compared survival only among cases that reported use of a wireless phone. There was no significant difference in survival between ipsilateral and contralateral use of a mobile phone $(\mathrm{p}=0.95)$. Median survival of astrocytoma cases with ipsilateral use of a mobile phone was 460 days and for contralateral 543 days. Similarly, no significant differences were found for astrocytoma grade I-II and astrocytoma grade III-IV in separate calculations.

The same analysis for use of cordless phone gave no significant differences in survival for patients with astrocytoma 
Table VIII. Odds ratio (OR) and 95\% confidence interval (CI) for gender-specific analysis of acoustic neuroma. ${ }^{\mathrm{a}}$

Age at first exposure/

Type of telephone

All Ca/Co OR (CI) Ipsilateral + Ipsi/contralateral Ca/Co OR (CI) Contralateral Ca/Co OR (CI)

\begin{tabular}{|c|c|c|c|}
\hline \multicolumn{4}{|l|}{$\operatorname{Men}(n=105)$} \\
\hline Mobile phone, & $76 / 503$ & $47 / 215$ & $28 / 165$ \\
\hline \multirow[t]{2}{*}{$>1$ year latency } & 2.3 & 2.4 & 2.1 \\
\hline & $1.4-3.8$ & $1.3-4.2$ & $1.1-4.0$ \\
\hline \multirow[t]{3}{*}{$>10$ year latency } & $15 / 84$ & $10 / 38$ & $5 / 24$ \\
\hline & 2.9 & 3.2 & 3.2 \\
\hline & $1.3-6.4$ & $1.3-8.1$ & $0.98-11$ \\
\hline \multirow{3}{*}{$\begin{array}{l}\text { Cordless phone, } \\
>1 \text { year latency }\end{array}$} & $45 / 318$ & $32 / 142$ & $13 / 104$ \\
\hline & 2.0 & 2.1 & 1.7 \\
\hline & $1.1-3.5$ & $1.1-4.0$ & $0.8-3.8$ \\
\hline \multirow[t]{3}{*}{$>10$ year latency } & $1 / 31$ & $1 / 13$ & $0 / 12$ \\
\hline & 0.6 & 1.2 & - \\
\hline & $0.1-5.6$ & $0.1-12$ & \\
\hline \multicolumn{4}{|l|}{ Women $(n=138)$} \\
\hline \multirow{3}{*}{$\begin{array}{l}\text { Mobile phone, } \\
>1 \text { year latency }\end{array}$} & $54 / 397$ & $33 / 159$ & $20 / 143$ \\
\hline & 1.3 & 1.4 & 1.0 \\
\hline & $0.8-1.9$ & $0.9-2.4$ & $0.6-1.8$ \\
\hline \multirow[t]{3}{*}{$>10$ year latency } & $5 / 15$ & $3 / 7$ & $1 / 5$ \\
\hline & 3.5 & 3.1 & 1.6 \\
\hline & $1.2-11$ & $0.8-13$ & $0.2-14$ \\
\hline \multirow{3}{*}{$\begin{array}{l}\text { Cordless phone, } \\
>1 \text { year latency }\end{array}$} & $51 / 383$ & $35 / 167$ & $15 / 131$ \\
\hline & 1.2 & 1.4 & 0.8 \\
\hline & $0.8-1.9$ & $0.9-2.4$ & $0.4-1.5$ \\
\hline \multirow[t]{3}{*}{$>10$ year latency } & $3 / 14$ & $2 / 2$ & $1 / 8$ \\
\hline & 2.2 & 7.5 & 1.1 \\
\hline & $0.6-8.5$ & $0.97-58$ & $0.1-9.2$ \\
\hline
\end{tabular}

${ }^{a}$ Numbers of exposed cases $(\mathrm{Ca})$ and controls $(\mathrm{Co})$ are given. Adjustment was made for age, SEI and year of diagnosis.

reporting ipsilateral use compared with contralateral use $(\mathrm{p}=0.87)$. Median survival for ipsilateral use was 529 days and for contralateral 569 days. No significant differences were found in the groups astrocytoma grade I-II and grade III-IV.

Incidence of brain tumours. We analysed the incidence of brain tumours (ICD-7=193.0) using the Swedish Cancer Registry, available on line (http://www.socialstyrelsen.se/ Statistik/statistikdatabas/index.htm). Results are shown for the whole time period 1970-2007 and for different decades, age adjusted to the world standard population, Table IX. During the whole period the annual age adjusted incidence increased significantly for all brain tumours with $+0.28 \%, 95 \%$ $\mathrm{CI}=+0.04$ to +0.52 . After declining during 1990-1999 an increasing incidence was found during 2000-2007 (+0.56\%, $95 \% \mathrm{CI}=-0.99$ to +2.13$)$. The age-adjusted incidence of astrocytoma increased during 2000-2007 yearly with $+1.55 \%$, $95 \% \mathrm{CI}=-0.15$ to +3.27 , significantly so among women. In the age group $>19$ years the annual change was significant for astrocytoma, $+2.16 \%, 95 \% \mathrm{CI}=+0.25$ to +4.10 .

The annual age-adjusted incidence of acoustic neuroma increased significantly for the time period 1970-2007 with $+2.12 \%, 95 \% \mathrm{CI}=+1.22$ to +3.02 . However, during 2000-2007 a significantly decreasing incidence was found, $-7.10 \%, 95 \%$ $\mathrm{CI}=-12.4$ to -1.42 .

Using data published in 'Cancer Incidence in Sweden' (2000-2007), available on line, it is possible to analyse the incidence of nervous system tumours (ICD-7=193) for the time period 2000-2007 in the 6 different medical regions of Sweden reporting to the Cancer Registry, age adjusted according to the Swedish population January 1, 2000. Interestingly, a significantly increasing incidence was found in Gothenburg region $(\mathrm{p}<0.01)$ for both men and women whereas all other regions showed for both genders a declining incidence, for example the Stockholm region $(\mathrm{p}=0.053$ for men, $p=0.27$ for women), Fig. 1 . The age adjusted incidence in the Stockholm medical region was in 2007 for men 8.8 per 100,000 person years and for women 11.0. The corresponding rates in Gothenburg medical region were 19.3 for men and 18.8 for women.

\section{Discussion}

The main results in our further analyses are consistent with a finding of an increased risk for ipsilateral astrocytoma and acoustic neuroma for use of both mobile and cordless phone. 
Table IX. Estimated change in incidence rate/year $(\%)$ and $95 \%$ confidence interval (CI) for all brain tumours, astrocytoma grade I-IV and acoustic neuroma in Sweden 1970-2007. a

\begin{tabular}{|c|c|c|c|c|c|c|}
\hline & \multicolumn{2}{|c|}{ Brain tumour, all } & \multicolumn{2}{|c|}{ Astrocytoma grade I-IV } & \multicolumn{2}{|c|}{ Acoustic neuroma } \\
\hline & $\begin{array}{c}\text { Change in incidence } \\
\text { rate/year }(\%)\end{array}$ & $95 \% \mathrm{CI}$ & $\begin{array}{c}\text { Change in incidence } \\
\text { rate/year }(\%)\end{array}$ & $95 \% \mathrm{CI}$ & $\begin{array}{c}\text { Change in incidence } \\
\text { rate/year }(\%)\end{array}$ & $95 \% \mathrm{CI}$ \\
\hline \multicolumn{7}{|l|}{ Total } \\
\hline 1970-2007 & +0.28 & $0.04,0.52$ & +0.05 & $-0.20,0.30$ & +2.12 & $1.22,3.02$ \\
\hline$-1970-1979$ & -0.15 & $-1.48,1.20$ & -0.16 & $-1.75,1.46$ & -1.66 & $-9.83,7.24$ \\
\hline$-1980-1989$ & +2.03 & $0.60,3.47$ & +2.53 & $1.39,3.69$ & +4.96 & $-0.34,10.5$ \\
\hline$-1990-1999$ & -0.32 & $-1.34,0.71$ & -0.33 & $-1.74,1.11$ & +0.72 & $-2.08,3.60$ \\
\hline$-2000-2007$ & +0.56 & $-0.99,2.13$ & +1.55 & $-0.15,3.27$ & -7.10 & $-12.4,-1.42$ \\
\hline \multicolumn{7}{|l|}{ Men } \\
\hline 1970-2007 & +0.13 & $-0.15,0.41$ & +0.12 & $-0.18,0.42$ & +2.82 & $1.78,3.88$ \\
\hline$-1970-1979$ & -0.77 & $-2.47,0.96$ & -1.19 & $-3.55,1.23$ & -1.16 & $-12.0,11.0$ \\
\hline$-1980-1989$ & +1.41 & $-0.46,3.30$ & +1.72 & $-0.55,4.04$ & +7.29 & $0.45,14.6$ \\
\hline$-1990-1999$ & -0.93 & $-1.97,0.12$ & -0.21 & $-1.63,1.24$ & -0.29 & $-2.92,2.42$ \\
\hline$-2000-2007$ & -0.17 & $-1.94,1.63$ & +0.74 & $-1.67,3.21$ & -6.97 & $-14.5,1.18$ \\
\hline \multicolumn{7}{|l|}{ Women } \\
\hline 1970-2007 & +0.44 & $0.20,0.69$ & -0.03 & $-0.35,0.28$ & +1.61 & $0.64,2.59$ \\
\hline$-1970-1979$ & +0.56 & $-0.86,2.01$ & +1.21 & $-0.78,3.24$ & -1.82 & $-10.4,7.62$ \\
\hline$-1980-1989$ & +2.65 & $1.26,4.05$ & +3.55 & $2.39,4.73$ & +3.31 & $-2.23,9.15$ \\
\hline$-1990-1999$ & +0.23 & $-1.21,1.70$ & -0.51 & $-3.02,2.06$ & +1.73 & $-2.63,6.29$ \\
\hline$-2000-2007$ & +1.27 & $-0.90,3.48$ & +2.67 & $0.69,4.68$ & -7.53 & $-12.7,-2.10$ \\
\hline \multicolumn{7}{|l|}{$\begin{array}{l}\text { Total, } \\
>19 \text { years old }\end{array}$} \\
\hline 1970-2007 & +0.22 & $-0.01,0.46$ & -0.01 & $-0.24,0.22$ & +2.12 & $1.24,3.00$ \\
\hline -1970-1979 & +0.15 & $-1.18,1.51$ & -0.12 & $-1.62,1.41$ & -1.66 & $-9.48,6.83$ \\
\hline$-1980-1989$ & +1.54 & $0.13,2.96$ & +2.10 & $0.75,3.48$ & +4.86 & $-0.37,10.4$ \\
\hline$-1990-1999$ & -0.25 & $-1.20,0.71$ & -0.15 & $-1.63,1.34$ & +0.66 & $-1.85,3.23$ \\
\hline$-2000-2007$ & +1.26 & $-0.62,3.18$ & +2.16 & $0.25,4.10$ & -7.08 & $-12.5,-1.30$ \\
\hline
\end{tabular}

${ }^{\mathrm{a} C a l c u l a t i o n s ~ b a s e d ~ o n ~ i n c i d e n c e ~ r a t e s ~ a g e ~ a d j u s t e d ~ t o ~ t h e ~ w o r l d ~ s t a n d a r d ~ p o p u l a t i o n . ~}$

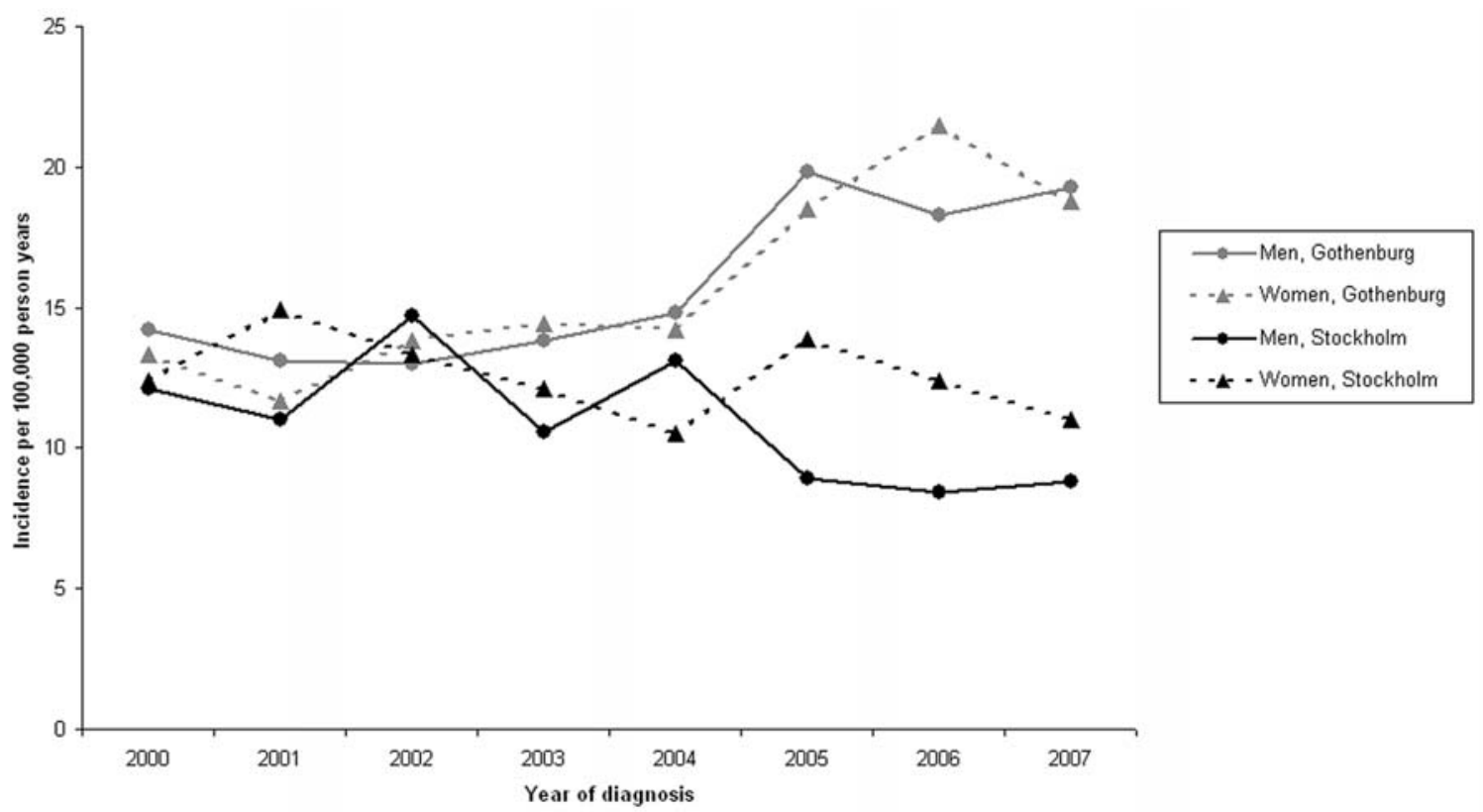

Figure 1. Incidence rates for nervous system tumours (ICD-7=193) in the Gothenburg and Stockholm medical regions, 2000-2007. Age adjusted to the Swedish population January 1,2000. 
Similar results were found when we stratified for gender. For astrocytoma we found an increased risk for tumour in the frontal, parietal or temporal lobe. The risk increased for both tumour types with time since first use and was highest in the group with $>10$ year latency. This is what one would expect for a carcinogenic effect from radiofrequency fields emitted from wireless phones. The brain is a near-field organ for such exposure, thus all use in a car with external antenna or a handsfree was disregarded. We included in the ipsilateral group all use $\geq 50 \%$ on the tumour side of the head. This is in contrast to our previous analyses where ipsilateral was defined as $>50 \%$ use and contralateral $<50 \%(16,17)$. With the now used definition we could include in the calculations the subjects with varying side, that is equally both sides during phone calls, previously analyzed separately.

Especially worrying is the finding of highest risk in persons with first use at age $<20$ years. This was found both for astrocytoma and acoustic neuroma, except use of cordless phone for the latter tumour, however with only one exposed case. This result is of biological significance since a developing organ is more sensitive for carcinogenic agents and the brain is continuing to develop until $\sim 20$ years of age. Cases that had used wireless phones were younger than non-users. To evaluate if such microwave exposure influenced astrocytoma growth we analysed age at diagnosis and latency for ipsilateral and contralateral use, however without finding any significant differences. There was no significant difference in survival for cases with astrocytoma with ipsilateral use compared with contralateral use. Thus, these analyses did not indicate that ipsilateral wireless phone use had a major impact on tumour growth or latency compared with contralateral use, but should be interpreted with caution since also contralateral mobile phone use increased the risk in the $>10$ year latency group.

It is notable with regard to malignant brain tumour that increased risk was only found for astrocytoma as we have published previously. This type of tumour is a glioma and was included in our review and meta-analysis $(6,7)$. Regarding mechanism for microwave carcinogenesis the astrocytoma finding is of interest, as discussed below.

The results were based on our two consecutive population based case control studies on incident brain tumour cases for the time period 1997-2003. Controls were drawn from the population registry. Exposure was assessed by a questionnaire that was supplemented over the phone, if necessary. In order to get good quality on the information only living cases and controls were included. Thus, deceased patients were excluded, but those with a malignant brain tumour have been included in a further case control study with also deceased controls. These results are to be published separately.

Cases were reported from the regional cancer registries in the study areas. All had histopathological verification of the diagnosis, but if it was unclear copies were obtained from the various pathology departments. Also regarding tumour localisation we received detailed information, mostly based on records from radiology departments. In some instances, e.g. side of an acoustic neuroma, this could be obtained from the report to the cancer registry, but usually radiology records were used.

The case participation was good in our studies, $88 \%$ for cases with benign brain tumours, $90 \%$ for malignant brain tumour cases and $89 \%$ for the controls. One explanation to the high response rate might be that the two studies were hospitalbased with many physicians in the research group. Also our study method with questionnaires sent home, usually for cases a couple of months after diagnosis, probably improved the response rate. Thus, cases and controls could answer the questionnaire in a relaxed situation and if necessary give additional information over the phone. Case and control status was obscured during this procedure. Our findings of different risk for different tumour types, increasing risk for latency and ipsilateral use of the wireless phone and no protective effect (decreased OR) for contralateral use strongly argue against both observational and recall bias as an explanation of the findings.

Our method has been judged to be quite superior to the methods in the Interphone studies where computer aided personal interviews were performed, even bedside for the cases (20). Obviously the many different interviewers knew if it was a case or a control that was interviewed. Case participation varied from 37 to $93 \%$ and control participation from 42 to $75 \%$ in the Interphone studies. Low participation rates for cases and controls might give selection bias and influence the results in the Interphone studies. We have discussed these and other shortcomings in the Interphone studies elsewhere $(7,21)$.

All use of wireless phones using $>1$-year latency period were included in our studies. Time period for use was assessed including type of phone. Average number of minutes per day was asked for so that total number of hours over the years could be calculated. The unexposed group included subjects with no use or use of wireless phones with $\leq 1$ year latency period. On the contrary, mobile phone use in the Interphone studies was defined as 'regular use' on average once per week during at least 6 months, less than that was regarded as unexposed including also all use within $<1$ year before diagnosis. This definition of 'regular use' seems to have been arbitrary chosen and might have created both observational and recall bias in the interpretation of such a vague definition.

Use of cordless phones was not assessed in most Interphone studies, in a couple of studies said to have been assessed but with no results clearly presented $(22,23)$. Cordless phones have a median power in the same magnitude as GSM phones (24). They are also used for longer calls than mobile phones $(16,17)$. Including use of cordless phones in the 'unexposed' group, as in the Interphone studies, would thus underestimate the risk and bias OR against unity.

Of interest is our consistent finding of an increased risk for astrocytoma associated with use of both mobile phones and cordless phones. Several animal studies have shown dysfunction of the blood-brain barrier (BBB) caused by radiofrequency fields $(25,26)$. Leakage of albumin into the brain has been demonstrated. The BBB consists of endothelial cells and endfeets of astrocytes. Thus, one mechanism might be that microwaves induce BBB dysfunction so that carcinogenic substances may leak into the brain whereby especially the astrocytes might be exposed. There is some support for that mechanism in our study since we found an increased risk for astrocytoma but not consistently so for other types of malignant brain tumours. Of course also an 
interaction with microwaves per se might exist since microwaves have been shown to induce several non-thermal effects in experimental studies, including free radicals (27).

Clearly an association between use of mobile or cordless phone and acoustic neuroma was also found. This tumour type is of interest since it is located in an anatomical area with high ipsilateral exposure. One of the first signs of an acoustic neuroma is hearing difficulties. This leads usually to a shift of the ear used during phone calls. Thus it is of importance to assess laterality of phone use for the whole time period and not only most recent use. We were careful about this point for all tumour types. Regarding meningioma there was a tendency to higher OR in the $>10$ year latency group. However, the results were of borderline significance. It is thus pertinent to wait for results from studies with longer latency periods.

In an editorial in the Swedish Medical Association Journal it was claimed that not much confidence can be attributed to our results of an association between mobile phones and brain tumours since the incidence has not been rising according to the Swedish Cancer Registry (28). However, the completeness of the Swedish Cancer Registry has been seriously questioned (29). Thus, in the year 1998 as many as $13.9 \%$ of nervous system tumours were reported to the Hospital Discharge Registry only, but not to the Cancer Registry. From county hospitals $121.1 \%$ were never reported and university hospitals missed to report $48.2 \%$ to the Cancer Registry. In males aged $>70$ years $43.9 \%$ were never reported and the correspoding frequency for females aged $>70$ years was $29.6 \%$.

With such large deficits the Swedish Cancer Registry is not reliable to use to determine time trends for brain tumours. Interestingly, in spite of this deficit in the Cancer Registry we found significantly incrasing incidence for brain tumours during the time period 1970-2007. We found for astrocytoma grade I-IV a sharp and significant increase of the incidence during 2000-2007 for subjects $>19$ years. Considering a tumour induction period of mostly at least 10 years it seems to be justified to analyse that age group and exclude the younger ones. Use of mobile and cordless phones increased rapidly from mid 1990s in Sweden, so these results strengthen our results of an association between wireless phones and brain tumours, since there is no other known risk factor for brain tumours that has been recently introduced in Sweden. It is noteworthy that we found an attributable fraction of $16.8 \%$ for astrocytoma.

Taking the still relatively short time for use of wireless phones on a broad scale $(30,31)$ the results showing increasing brain tumour incidence may be early warning of future public health problems, especially considering the large deficit in the Swedish Cancer Registry. It is striking that during 2000-2007 the incidence of nervous system tumours increased significantly in the Gothenburg medical region, which seems to have better reporting than other medical regions in Sweden. The incidence in that region was in 2007 about two times higher than in Stockholm medical region, and there is no other explanation for that than missing data from the Stockholm region. Similar results were also found comparing Gothenburg area with the other four medical regions in Sweden. In spite of this we found significantly increasing incidence for astrocytoma during 2000-2007 in Sweden which is worrying since due to missing data the true increase would even be higher.
The annual age-adjusted incidence of acoustic neuroma increased significantly during 1970-2007, but in contrast to the finding for astrocytoma decreased significantly during 2000-2007. Today the diagnosis is usually based on CT and MRI, so surgery to determine histopathology is thus not always necessary. This is a rare tumour type and centralisation of therapy using e.g. the $\gamma$ knife $(32,33)$ may partly explain these findings especially since it seems as if some brain tumours from the Stockholm area are apparently omitted from the Cancer Registry. Another possibility is also that patients with this often slowly growing tumour may be on surveillance with MRI without active treatment and might thus not be reported to the Cancer Registry. Thus these results from analysis of incidence data are not consistent with an association between use of wireless phones and acoustic neuroma. We calculated the attributable fraction to be $20.4 \%$ in our studies. However, our results are of biological relevance and considering the large deficit in reporting of nervous system tumours to the Swedish Cancer Registry makes a comparison of incidence data with our results less reliable for such a rare tumour type.

In summary, we report a consistent association between use of mobile or cordless phones and astrocytoma grade I-IV and acoustic neuroma. The risk is highest for ipsilateral exposure to microwaves using $>10$ year latency period. We found an especially high risk for persons that started use of mobile or cordless phones before the age of 20 years, although based on low numbers. The results are supported by increasing incidence of astrocytoma during 2000-2007 in Sweden, significantly so for subjects $>19$ years old.

\section{Acknowledgements}

Supported by grants from Cancer-och Allergifonden, Cancerhjälpen and Örebro Cancer Fund. Valuable comments by Cindy Sage, MA are acknowledged.

\section{References}

1. Hardell L and Sage C: Biological effects from electromagnetic field exposure and public exposure standards. Biomed Pharmacother 62: 104-109, 2008.

2. Cardis E, Deltour I, Mann S, et al: Distribution of RF energy emitted by mobile phones in anatomical structures of the brain. Phys Med Biol 53: 2771-2783, 2008.

3. Irigaray P, Newby JA, Clapp R, et al: Lifestyle related factors and environmental agents causing cancer: an overview. Biomed Pharmacother 61: 640-658, 2007.

4. Belpomme D, Irigaray P, Hardell L, et al: The multitude and diversity of environmental carcinogens. Environ Res 105: 4141-4129, 2007.

5. Belpomme D, Irigaray $\mathrm{P}, \mathrm{Sasco} \mathrm{AJ}$, et al: The growing incidence of cancer: role of lifstyle and screening detection (Review). Int J Oncol 30: 1037-1049, 2007.

6. Hardell L, Carlberg M, Söderqvist F, Hansson Mild K and Morgan LL: Long-term use of cellular phones and brain tumours: increased risk associated with use for $\geq 10$ years. Occup Environ Med 64: 626-632, 2007.

7. Hardell L, Carlberg M, Söderqvist F and Hansson Mild K: Meta-analysis of long-term mobile phone use and the association with brain tumours. Int J Oncol 32: 1097-1103, 2008.

8. Hardell L, Näsman A, Påhlson A, Hallquist A and Hansson Mild K: Use of cellular telephones and the risk for brain tumours: A case-control study. Int J Oncol 15: 113-116, 1999.

9. Hardell L, Hansson Mild K, Påhlson A and Hallquist A: Ionizing radiation, cellular telephones and the risk for brain tumours. Eur J Cancer Prev 10: 523-529, 2001.

10. Hardell L, Hallquist A, Hansson Mild K, Carlberg M, Påhlson A and Lilja A: Cellular and cordless telephones and the risk for brain tumours. Eur J Cancer Prev 11: 377-386, 2002. 
11. Hardell L, Hansson Mild K and Carlberg M: Case-control study on the use of cellular and cordless phones and the risk for malignant brain tumours. Int J Radiat Biol 78: 931-936, 2002.

12. Hardell L, Hansson Mild K and Carlberg M: Further aspects on cellular and cordless telephones and brain tumours. Int J Oncol 22: 399-407, 2003

13. Hardell L, Hansson Mild K, Carlberg M, Hallquist A and Påhlson A: Vestibular schwannoma, tinnitus and cellular telephones. Neuroepidemiology 22: 124-129, 2003.

14. Hardell L, Carlberg M and Hansson Mild K: Case-control study on cellular and cordless telephones and the risk for acoustic neuroma or meningioma in patients diagnosed 2000-2003. Neuroepidemiology 25: 120-128, 2005.

15. Hardell L, Carlberg M and Hansson Mild K: Case-control study of the association between the use of cellular and cordless telephones and malignant brain tumours diagnosed during 2000-2003. Environ Res 100: 232-241, 2006.

16. Hardell L, Carlberg M and Hansson Mild K: Pooled analysis of two case-control studies on use of cellular and cordless telephones and the risk for malignant brain tumours diagnosed in 1997-2003. Int Arch Occup Environ Health 79: 630-639, 2006

17. Hardell L, Carlberg M and Hansson Mild K: Pooled analysis of two case-control studies on the use of cellular and cordless telephones and the risk of benign brain tumours diagnosed during 1997-2003. Int J Oncol 28: 509-518, 2006.

18. Hardell L, Hansson Mild K, Carlberg M and Hallquist A: Cellular and cordless telephones and the association with brain tumours in different age group. Arch Environ Health 59: 132-137, 2004.

19. Inskip $\mathrm{P}$, Tarone $\mathrm{R}$, Hatch $\mathrm{E}$, et al: Cellular-telephone use and brain tumors. N Engl J Med 344: 79-86, 2001.

20. Kundi: The controversy about possible relationship between mobile phone use and cancer. Env Health Perspect 117: 316324, 2009.

21. Hardell L, Carlberg M and Mild KH: Methodological aspects of epidemiological studies on the use of mobile phones and their association with brain tumors. Open Env Sciences 2: 54-61, 2008

22. Lönn S, Ahlbom A, Hall P and Feychting M: Long-term mobile phone use and brain tumor risk. Am J Epidemiol 161: 526-535, 2005 .
23. Schüz J, Böhler E, Berg G, et al: Cellular phones, cordless phones, and the risks of glioma and meningioma (Interphone Study Group, Germany). Am J Epidemiol 163: 512-520, 2006.

24. Hansson Mild K, Hardell L, Kundi M and Mattsson MO: Mobile phones and cancer: Is there really no evidence of an association? (Review) Int J Mol Med 12: 67-72, 2003

25. Orendacova J, Orendac M, Racekova E and Marsala J: Neurobiological effects of microwave exposure: a review focused on morphological findings in experimental animals. Arch Ital Biol 145: 1-12, 2007

26. Nittby H, Grafstrom G, Eberhardt JL, et al: Radiofrequency and extremely low-frequency electromagnetic field effects on the blood-brain barrier. Electromagn Biol Med 27: 103-126, 2008.

27. Sage $C$ and Carpenter D (eds): BioInitiative Report: A Rationale for a Biologically-based Public Exposure Standard for Electromagnetic Fields (ELF and RF). http://www.bioinitiative. org/(assessed February 15, 2009)

28. Milerad J: Många cancerlarm från samma källa, In Swedish (Many cancer alarms from the same source). Läkartidningen 104: 49-50, 2007.

29. Barlow L, Westergren K, Holmberg L and Talbäck M: The completeness of the Swedish Cancer Register - a sample survey for year 1998. Acta Oncol 48: 27-33, 2009.

30. Söderqvist F, Hardell L, Carlberg M and Hansson Mild K: Ownership and use of wireless telephones: a population-based study of Swedish children aged 7-14 years. BMC Public Health 7: $105,2007$.

31. Söderqvist F, Carlberg $M$ and Hardell L: Use of wireless telephones and self-reported health symptoms: a populationbased study among Swedish adolescents aged 15-19 years. Environ Health 7: 18, 2008.

32. Lasak JM, Klish D, Kryzer TC, Hearn C, Gorecki JP and Rine GP: Gamma knife radiosurgery for vestibular schwannoma: early hearing outcomes and evaluation of the cochlear dose. Otol Neurotol 29: 1179-1186, 2008.

33. Linskey ME: Hearing preservation in vestibular schwannoma stereotactic radisurgeery: what really matters? J Neurosurg 109 (Suppl): 129-136, 2008. 